\title{
Response to: Comment on 'Are patients with poorer vision more polite? A study examining door closing tendencies in patients with poor vision'
}

\author{
S. Wijetilleka ${ }^{1} \cdot$ G. Williams ${ }^{1}$
}

Received: 24 October 2018 / Accepted: 25 October 2018 / Published online: 27 November 2018

(c) The Royal College of Ophthalmologists 2018

We, the authors, thank Dr Joshua Harvey for supplying a very valid list of possible confounding factors affecting our study. We certainly agree that age is a confounding factor, with younger patients with good vision less likely to close the door behind them in clinic. We are somewhat surprised to hear that living in London may be a protective factor and suggest that Welsh patients are on the whole equally, if not more, polite, with one of the authors having worked at both locations. It may be the case, however, that the English place more value on the superficial manifestation of politeness in such acts as door closing, and therefore we suggest including an anthropologist in any future largescale study to examine significant cultural differences between the various nations that make up the United
Kingdom. The authors also debate some of the other listed confounding factors, including how a person's marital status and diet could confound their ability to close a door behind them after leaving clinic, although it was considered beyond the scope of the study to evaluate these. The authors certainly support the idea of further research into the subject and the first UK-wide multicentre study on door closing outcomes considering these factors is a valid idea.

\section{Compliance with ethical standards}

Conflict of interest The authors declare that they have no conflict of interest.

\section{S. Wijetilleka}

sidwijetilleka@doctors.net.uk

1 Singleton Hospital, Sketty Lane, Swansea, UK 